\title{
Six Strand Repair and Early Range of Motion in Management of Flexor Tendon Injury
}

W.A.Kandil, O.M.Essawy and A,M.Fawzi

Orthopedic Surgery Dept., Faculty of Medicine, Benha Univ., Benha, Egypt

E-Mail: dr.ahmedsarhan2012@gmail.com

\begin{abstract}
Ligament fixes with 6-strands withstand joined dynamic and inactive finger movements. The crack rate is lower with the utilization of multi-strand fixes contrasted and those after customary 2-strand fixes. In any case, no randomized Prospective clinical examinations have explored this specific inquiry. Strategy: We talked about the clinical consequences of flexor ligaments fix utilizing six-strand stitch procedure to fix flexor ligaments in 46 fingers of 22 patient. fingers were effectively activated promptly postoperative in a defensive brace. The follow - up period normal 12.7 months. Result:91\% of cases accomplished great to brilliant outcomes dependent on Strickland assessment framework and break rate was $4 \%$ of the cases. Determination: The utilization of a solid, hole safe stitch procedure like the six strand twofold circle method utilized in the current examination followed by the use of early postoperative controlled movement restoration brings about $91 \%$ superb and great postoperative scope of movement.
\end{abstract}

Keywords: Early mobilization, Six-strand repair.

\section{Introduction}

Flexor ligament wounds stay a moving condition to figure out how to guarantee ideal result for the patient. Since Kirchmayr depicted the principal flexor ligament fix in 1917, a few ways to deal with flexor ligament injury have empowered effective fixes paces of $70-90 \%$. Essential careful fix brings about better practical result contrasted with auxiliary fix or ligament unite a medical procedure.

Flexor ligament injury fix has been widely investigated and the writing shows effective fix requires negligible gapping at the maintenance site or impedance with ligament vascularity, secure stitch hitches, smooth intersection of ligament end and having adequate strength for mending. Nonetheless, the specific careful way to deal with make progress being presently utilized among specialists is as yet dubious [1].

While the changed Kessler fix is as yet utilized for the center ligament stitch, hand specialists are utilizing multistrand fixes, for example, twofold Kessler fixes, cruciate fixes, 4-strand and 6-strand circled stitch fixes savage and its adjustments. Twofold Kessler, 4-or 6strand fixes of harmed ligaments were accounted for by specialists in European nations, USA, and Australia. The circled stitch ligament fixes are more well known in Asian nations, for example, Japan, China and Singapore [2]. Ligaments fix with 6-strands withstand consolidated dynamic and latent finger movements. The break rate is lower with the utilization of multi-strand fixes contrasted and those after customary 2-strand fixes. Nonetheless, no randomized Prospective clinical examinations have explored this specific inquiry [3].

Conventions for the early use of inactive and dynamic wrist and advanced movement as a way to all the more quickly increment the strength and floating of fixed ligaments. Preparation following flexor ligament fix is fundamental for mending and fix.

It has been indicated tentatively that early movement animates ligament recuperating and diminishes grip [4]. Early assembly is the most ordinarily detailed strategy for dealing with the mending flexor ligament. With such countless decisions, the present hand advisor should comprehend what those decisions are, yet in addition why and when to utilize them. There is nobody right approach to deal with a fixed flexor ligament; the expert who doesn't see how current strategies developed is unprepared to plan the suitable treatment for a given patient [5].

\section{Patient and methods}

\subsection{Study design}

We directed forthcoming randomized controlled preliminary from february 2019 till July 2020, 22 patients with 46 intense flexor ligament sores were concentrated tentatively, where essential flexor ligament fix was done and afterward the patients were followed up for a normal term of 12.7 months (going from 5 - year and a half).

\subsection{Patients}

The study represents the management of 46 finger lesions ( 1 zone I, 17 zone II, 6 zone III, 3 zone IV, 19 zone $\mathrm{V}$ ) and 1 thumb lesions in zone IV.

\section{I-Criteria of inclusion of patients:}

- Acute flexor tendon injury.

- Single or multiple flexor tendons injury

- Any age and sex.

- Co-operative medically healthy patients.

\section{II-Criteria of exclusion of patients:}

- Old, neglected injuries.

- Failed repaired tendons.

- Re ruptured tendon injuries.

- Associated neurovascular injury.

- Associated overlying skin loss.

- Underlying bone fractures.

- Patients who are medically un-fit for operations.

\subsection{Preoperative assessment}

All patients were assessed clinically and radiologically by different means. 


\subsection{Operative technique}

The first "six stranded" suture technique is thought to be strong enough to allow early active movement of the finger, and thus to avoid some of the problems of controlled dynamic mobilization. This method of using three grasping stitches in a continuous fashion was applied to plump, oval or round tendons; for flat tendons interrupted sutures were used, for small tendons (e.g. profundus of the little finger) two grasps were used and for very thin tendons (e.g. superficialis distal to its division) only one grasp was used [3]

\subsection{Technique}

Comprised three grasping stitches in each tendon end and six strands of 4/ 0 Ethibond suture material (braided polyester, Ethicon Ltd, Edinburgh). To make the grasping stitch (Fig. 1), the needle entered the tendon end, emerged at $\mathrm{A}$, reentered at $\mathrm{B}$, emerged opposite $\mathrm{D}$, re-entered at $\mathrm{C}$, emerged opposite $\mathrm{C}$, re-entered at $\mathrm{D}$, emerged opposite $\mathrm{B}$, re-entered at $\mathrm{E}$ and finally came out of the tendon end.

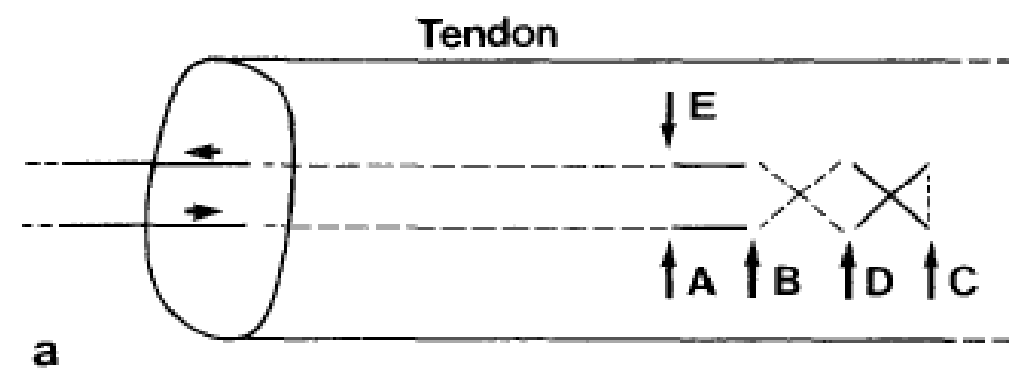

Fig. (1) Technique for the six-strand repair. (a) Insertion of one of the grasping stitches.

Six such grasping stitches, each about 1 to $1.5 \mathrm{~mm}$ diameter and about 5 to $10 \mathrm{~mm}$ from the tendon end, were made sequentially around the tendon Fig $(2 \mathrm{c})$.

A practical point was to grip the tendon end with toothed forceps whilst inserting the suture, putting a small bundle of tendon fibers in tension where the grasping stitch was made. a fine "epitenon" suture of $6 / 0$ Prolene was used in the second half of the series. The fibrous tendon sheath was repaired, but only if snagging of the tendon could be avoided [3].

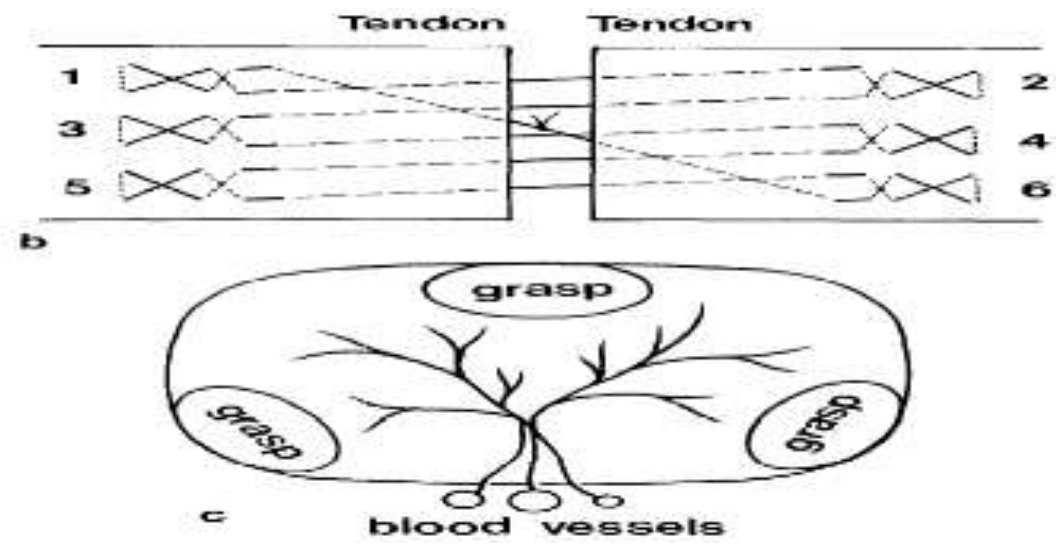

Fig. (2) (b) Six sequential stitches are used in this way. (c) They are distributed around the circumference of the tendon, avoiding the vincular area [3].

Yoshizu [6] introduced a new six-strand suture technique, called the Yoshizu \#1 technique, intended to maximize early active mobilization. The Yoshizu \#1 technique simplifies the six-strand suture technique because it comprises the commonly used Kessler and Tsuge techniques, and its average maximum load at a 3mm gap formation was reported to be $42 \mathrm{~N}$. This method satisfies most all of Tang's nine factors that affect the strength of a surgical repair (the number of suture strands, the tension of the repair, the core suture purchase, the type of tendon-suture junction, the diameter of the suture locks in the tendons) [6].

The tendon sheath opening was excised where sutured areas of tendons caught on the edges of their sheath windows and obstructed free movement. The A2 and A4 pulleys were not excised $\mathbf{T}$ completely, however, to prevent tendon bowstringing. All associated nerve divisions were repaired with 8-0 nylon, and all artery lacerations were not repaired. 

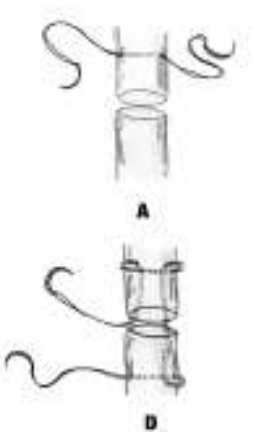

D

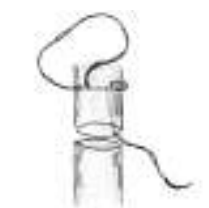

B

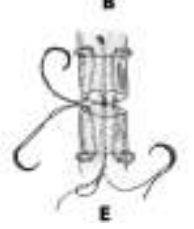

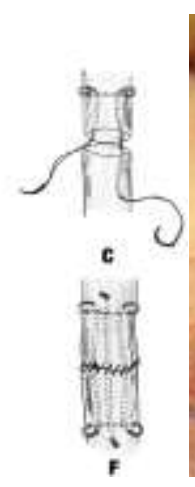

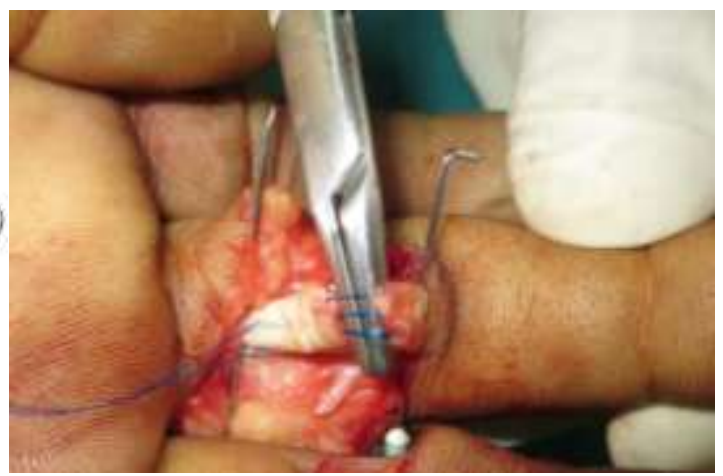

Fig. (3) The Yoshizu \#1 technique [6].

\subsection{Post-operative treatment}

Dorsal blocking splint used to hold the wrist 20-40 flexion the MP joints are flexed at least 60 degrees, and PIP and DIP joint in nearly full extension. Patient started active flexion of finger directly post operatively or can be delayed for couple of days tell patient tolerate pain. Mostly we include the four fingers, there has been a gradual trend toward decreasing the degree of wrist flexion in postoperative protective splint.

Postoperative rehabilitation is the corner stone of a successful treatment of recent flexor tendon lesions. We applied it on immediate postoperative. We employed the early active mobilization protocol, where it basically focuses on more global active motion. We aimed at actively mobilization all joints distal and proximal to the lesion from the DIP to elbow, all this procedure is carried out with the dorsal extension block splint.

\section{Results}

\section{According to Strickland [7] evaluation}

- Return of 85 - 100\% of active motion (excellent results) achieved in 34 finger.

- Return of $70-84 \%$ of achieve motion (good results) achieved in 8 finger.

- Fair results achieved in 1 finger.

- Poor results were achieved in 3fingers.

Table (1 ) Postoperative care. Early active mobilization.

\begin{tabular}{|c|c|}
\hline Dorsal Splint position & Motion allowed \\
\hline $\begin{array}{l}\text { Wrist } 30^{\circ} \text { flexion } \\
\text { MCP } 70^{\circ} \text { flexion } \\
\text { IP extended }\end{array}$ & $\begin{array}{c}0-3 \text { days } \\
\text { Anti edematous measures, limb elevation, active flexion allowed as } \\
\text { much as patient can }\end{array}$ \\
\hline $\begin{array}{l}\text { Wrist } 30^{\circ} \text { flexion } \\
\text { MCP } 70^{\circ} \text { flexion } \\
\text { IP extended } \\
\text { Wrist } 0^{\circ} \text { flexion } \\
\text { MCP } 50^{\circ} \text { flexion } \\
\text { IP extended }\end{array}$ & $\begin{array}{l}\qquad 0-2 \text { weeks } \\
\text { Encourage protected active finger flexion } \\
2-6 \text { weeks } \\
\text { Encourage protected active finger flexion }\end{array}$ \\
\hline $\begin{array}{l}\text { Intermittent splinting: removed during } \\
\text { exercise } \\
\text { Splinting at night } \\
\text { No splint }\end{array}$ & $\begin{array}{c}6 \text { weeks } \\
\text { Splint removed during exercise and patients continuous gliding } \\
\text { exercise, flexion extension of the wrist with finger full flexed. } \\
\text { Instruction to avoid simultaneous wrist and finger extension. } \\
\text { Blocking exercises begin if active tip to distal } \\
\text { palmar crease is more than } 3 \mathrm{~cm} \text { Passive extension can begin at } 7 \\
\text { weeks } \\
8 \text { weeks } \\
\text { Progressive resistive exercises initiated. } \\
14 \text { weeks } \\
\text { unrestricted use of hand }\end{array}$ \\
\hline
\end{tabular}

Return to professional activity is usually allowed after 3 months postoperatively to allow maximum recovery. 
Table (2) Result according Strickland evaluation.

\begin{tabular}{lll}
\hline Strickland & N & \\
\hline Excellent & 34 & \% \\
Good & 8 & 73.91 \\
Fair & 1 & 17.39 \\
Poor & 3 & 2.17 \\
Total & 46 & 0.0652 \\
\hline
\end{tabular}

\section{Analysis of result}

Overall results according to the digit involved:

Table (3) Relation between level of TAM and finger.

\begin{tabular}{|c|c|c|c|c|c|c|c|c|c|c|c|c|}
\hline \multirow{3}{*}{$\begin{array}{l}\text { Side of Injury } \\
\text { Finger }\end{array}$} & \multicolumn{10}{|c|}{ Level of TAM } & \multirow{2}{*}{\multicolumn{2}{|c|}{ Chi-Square }} \\
\hline & \multicolumn{2}{|c|}{ Excellent } & \multicolumn{2}{|c|}{ Good } & \multicolumn{2}{|c|}{ Fair } & \multicolumn{2}{|r|}{ Poor } & \multicolumn{2}{|c|}{ Total } & & \\
\hline & $\mathbf{N}$ & $\%$ & $\mathbf{N}$ & $\%$ & $\mathbf{N}$ & $\%$ & $\mathbf{N}$ & $\%$ & $\mathbf{N}$ & $\%$ & $\mathrm{X} 2$ & P-value \\
\hline Index & 4 & 23.53 & 4 & 16.00 & 0 & 0.00 & 1 & 33.33 & 9 & 19.57 & & \\
\hline Little & 3 & 17.65 & 7 & 28.00 & 0 & 0.00 & 1 & 33.33 & 11 & 23.91 & & \\
\hline Middle & 4 & 23.53 & 9 & 36.00 & 0 & 0.00 & 1 & 33.33 & 14 & 30.43 & & \\
\hline Ring & 5 & 29.41 & 5 & 20.00 & 1 & 100.00 & 0 & 0.00 & 11 & 23.91 & 7.642 & 0.812 \\
\hline THUMB & 1 & 5.88 & 0 & 0.00 & 0 & 0.00 & 0 & 0.00 & 1 & 2.17 & & \\
\hline Total & 17 & 100.00 & 25 & 100.00 & 1 & 100.00 & 3 & 100.00 & 46 & 100.00 & & \\
\hline
\end{tabular}

This table shows no statistically significant between level of TAM and finger.

\section{Results according to the zone of injury}

It was quite obvious that the zone with the most common controversy concerning the final results was zone II. Zone II constitutes the real challenge in flexor tendon surgery, followed by zone I. Zones III and V, IV on the contrary, promise very satisfactory results. Table (4) Final overall results according to the zone of injury.

Table (4) Shows the relation final results according to the zone involved.

\begin{tabular}{|c|c|c|c|c|c|c|c|c|c|c|c|c|}
\hline \multirow{3}{*}{$\begin{array}{l}\text { Side of Injury } \\
\text { Zone }\end{array}$} & \multicolumn{10}{|c|}{ Level of TAM } & \multirow{2}{*}{\multicolumn{2}{|c|}{ Chi-Square }} \\
\hline & \multicolumn{2}{|c|}{ Excellent } & \multicolumn{2}{|c|}{ Good } & \multicolumn{2}{|r|}{ Fair } & \multicolumn{2}{|c|}{ Poor } & \multicolumn{2}{|c|}{ Total } & & \\
\hline & $\mathbf{N}$ & $\%$ & $\mathbf{N}$ & $\%$ & $\mathbf{N}$ & $\%$ & $\mathbf{N}$ & $\%$ & $\mathbf{N}$ & $\%$ & $\mathrm{X} 2$ & P-value \\
\hline I & 0 & 0.00 & 1 & 4.00 & 0 & 0.00 & 0 & 0.00 & 1 & 2.17 & & \\
\hline II & 2 & 11.76 & $\begin{array}{l}1 \\
2\end{array}$ & 48.00 & 1 & 100.00 & 2 & 66.67 & $\begin{array}{l}1 \\
7\end{array}$ & 36.96 & $\begin{array}{c}22.1 \\
34\end{array}$ & $0.036^{*}$ \\
\hline III & 5 & 29.41 & 0 & 0.00 & 0 & 0.00 & 1 & 33.33 & 6 & 13.04 & & \\
\hline IV & 2 & 11.76 & 1 & 4.00 & 0 & 0.00 & 0 & 0.00 & 3 & 6.52 & & \\
\hline V & 8 & 47.06 & $\begin{array}{l}1 \\
1\end{array}$ & 44.00 & 0 & 0.00 & 0 & 0.00 & $\begin{array}{l}1 \\
9\end{array}$ & 41.30 & & \\
\hline Total & $\begin{array}{l}1 \\
7 \\
\end{array}$ & 100.00 & $\begin{array}{l}2 \\
5 \\
\end{array}$ & 100.00 & 1 & 100.00 & 3 & 100.00 & $\begin{array}{l}4 \\
6 \\
\end{array}$ & 100.00 & & \\
\hline
\end{tabular}




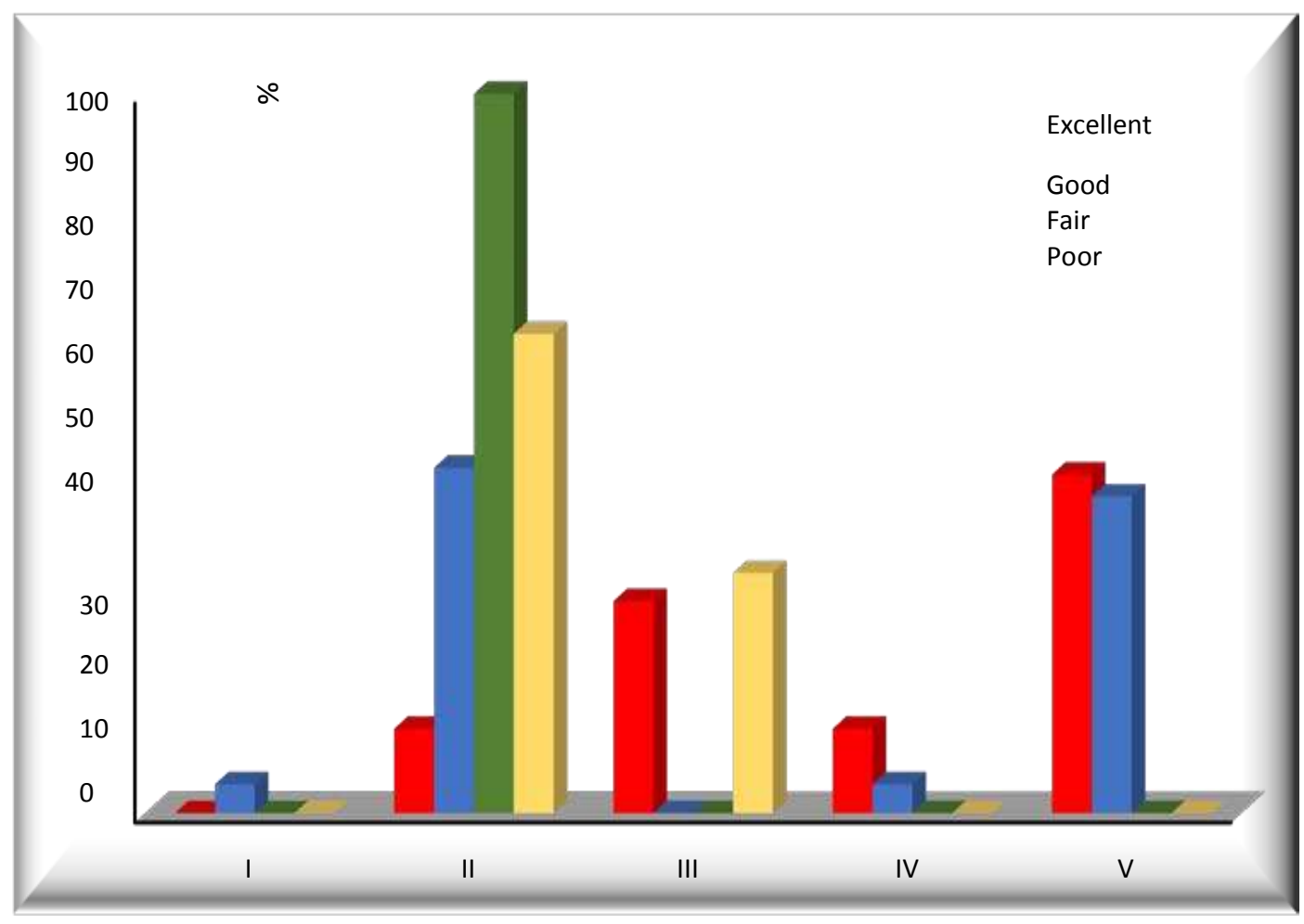

Fig (4) Shows the relation final results according to the zone involved

This table shows statistically significant between level of TAM and zone.

\section{Relation of final result and the nerve injury}

In our series, it is reported that no significant impact of nerve injures on the results of repair as illustrated in table 21. It's important to highlight that in our study the neurovascular repair did not interfere with applying our post-operative rehabilitation program.

Table (5) Relation of final result and the nerve injury.

\begin{tabular}{|c|c|c|c|c|c|c|c|c|c|c|c|c|}
\hline \multirow{3}{*}{ Neurological } & \multicolumn{10}{|c|}{ Level of TAM } & \multirow{2}{*}{\multicolumn{2}{|c|}{ Chi-Square }} \\
\hline & \multicolumn{2}{|c|}{ Excellent } & \multicolumn{2}{|c|}{ Good } & \multicolumn{2}{|c|}{ Fair } & \multicolumn{2}{|r|}{ Poor } & \multicolumn{2}{|c|}{ Total } & & \\
\hline & $\mathbf{N}$ & $\%$ & $\mathbf{N}$ & $\%$ & $\mathbf{N}$ & $\%$ & $\mathbf{N}$ & $\%$ & $\mathbf{N}$ & $\%$ & $\mathbf{X} 2$ & P-value \\
\hline No & 10 & 58.82 & 15 & 60.00 & 1 & 100.00 & 3 & 100.00 & 29 & 63.04 & & \\
\hline Yes & 7 & 41.18 & 10 & 40.00 & 0 & 0.00 & 0 & 0.00 & 17 & 36.96 & 2.574 & 0.462 \\
\hline Total & 17 & 100.00 & 25 & 100.00 & 1 & 100.00 & 3 & 100.00 & 46 & 100.00 & & \\
\hline
\end{tabular}

\section{Physio - compliance}

In our study there was a significant relation of the end result and the compliance of patients on physiotherapy program, and patients who had a physiotherapy specialist supervision had better result than the other practiced early motion program at home.

Table (6) Relation between physiotherapy compliance and TAM score.

\begin{tabular}{|c|c|c|c|c|c|c|c|c|c|c|c|c|}
\hline \multirow{3}{*}{ Physio compliance } & \multicolumn{10}{|c|}{ Level of TAM } & \multirow{2}{*}{\multicolumn{2}{|c|}{ Chi-Square }} \\
\hline & \multicolumn{2}{|c|}{ Excellent } & \multicolumn{2}{|c|}{ Good } & \multicolumn{2}{|r|}{ Fair } & \multicolumn{2}{|r|}{ Poor } & \multicolumn{2}{|c|}{ Total } & & \\
\hline & $\mathbf{N}$ & $\%$ & $\mathbf{N}$ & $\%$ & $\mathbf{N}$ & $\%$ & $\mathbf{N}$ & $\%$ & $\mathbf{N}$ & $\%$ & $\mathbf{X} 2$ & P-value \\
\hline Home physiotherapy & 0 & 0.00 & 1 & 4.00 & 1 & 100.00 & 2 & 66.67 & 4 & 8.70 & & \\
\hline Physiotherapy supervesion & 17 & 100.00 & 24 & 96.00 & 0 & 0.00 & 1 & 33.33 & 42 & 91.30 & & $0001 *$ \\
\hline Total & 17 & 100.00 & 25 & 100.00 & 1 & 100.00 & 3 & 100.00 & 46 & 100.00 & 012 & \\
\hline
\end{tabular}




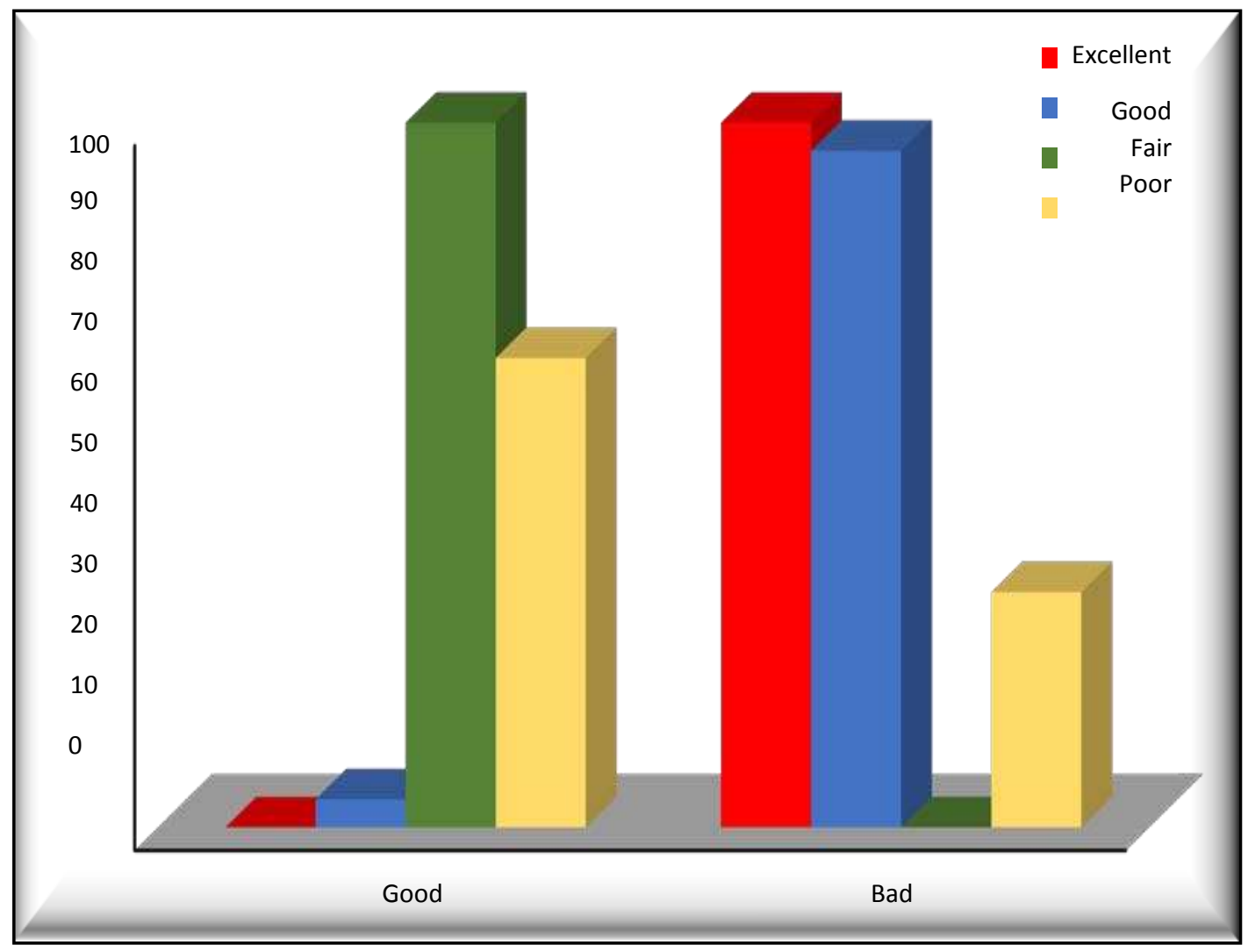

Fig (5) Graph shows the relation between physiotherapy compliance and TAM score.

\section{Overall incidence of complications}

The overall incidence of complications was $14.3 \%$ (6 digits with complications) Table (7) shows the incidence of each complication in relation to the whole series.

Table (7) Incidence of Complications in the study group.

\begin{tabular}{lcc}
\hline Complications & No. $[\mathbf{n = 6 ( 1 4 . 3 \% ) ]}$ & \% \\
\hline Infection & 1 & 2.17 \\
Rup & 2 & 4.35 \\
Skin contracture & 3 & 6.52 \\
\hline
\end{tabular}

\section{Discussion}

Biomechanical examines indicated the predominance of the elasticity of the six-strand stitch over the two and four strand strategies. The examinations indicated that the break strength is $24 \mathrm{~N}$ in regular Kessler fix, $38 \mathrm{~N}$ in 4-strand fix (Lee twofold circle), and $53 \mathrm{~N}$ in the Savage 4-strand fix. In the Savage 6-strand fix, the normal extreme strength before breakage is $84 \mathrm{~N}$. Fix strength increments with the quantity of center stitches. Activation following flexor ligament fix is fundamental for mending and fix.

It has been demonstrated tentatively that early movement invigorates ligament recuperating and diminishes attachment. Kleinert et al. also, Lister et al. were among the first to report astounding clinical outcomes utilizing dynamic augmentation detached flexion assembly with the guide of a powerful foothold brace. Comparative outcomes were accordingly announced by various creators. In any case, flexion contracture of the finger may create, and it has been hard to accomplish steady flexion of the distal interphalangeal joint.

LK Hung et.al [10] utilized the standard adjusted Kessler's to fix 46 digits in 32 patients with flexor ligament wounds. Understanding were being followed up for one year. Early dynamic activation of the fixed digit was started on the third postoperative day. The complete dynamic movement score of the American Society for Surgery of the Hand was estimated. The end-product did not regard amazing in $75 \%$. A thermoplastic dorsal support was utilized to keep up the wrist in 40 levels of flexion, the MCP joints at 70 flexion and dorsal augmentation block for the fingers at 0 .

Sandow et.al [11] led an examination utilizing a 4strand stitch procedure and embraced early dynamic activation as postoperative recovery convention. In their investigation they worked 73 ligament wounds in 52 patients. $71 \%$ of flexor digits fixed accomplished a 
decent or brilliant outcome grade with $34 \%$ of the fixes accomplishing an incredible result; $14 \%$ of fixes were reviewed as reasonable and $15 \%$ as helpless utilizing a similar appraisal strategy for our investigation Christiana et.al [8] detailed the clinical outcomes after fix of flexor ligament zone II wounds using a 6-strand twofold circle procedure and early post-usable dynamic recovery. It is reflectively investigated 22 patients including 51 cases with zone II flexor ligament fix utilizing a six-strand twofold circle strategy. The Strickland score for dynamic scope of movement (ROM) postoperatively was great and acceptable in most of the cases $(81 \%)$.

Hoffman et.al [9] performed an examination investigation of a six strand procedure with the two stand method (Kessler) indicated that the six strand bunch accomplished altogether better postoperative scope of movement. Assessment with the Strickland framework indicated $78 \%$ great and magnificent outcomes in the six strand bunch contrasted and $43 \%$ in the two strand gatherings .

Our examination addresses the administration of 46 finger injuries in 22 patients. Normal age was 33.05 years (goes from 23-48). The greater part of the patients who had been worked were manual laborers $66 \%$. A sixstrand procedure (Savage method) was utilized to fix the harmed ligaments in various hand zones (I-V). Early dynamic activation of the fixed digit was being started straightforwardly post operatively in defensive brace (wrist flexion 30o, MCP 70o, interphalangeal joint 0o expansion) we changed the support as endorsed in our convention. Follow-up period arrived at the midpoint of 12.7 months.

Osada et al. [13] Six-strand stitches utilizing the Yoshizu stitch strategy were utilized to fix flexor ligaments in 27 fingers from 21 back to back patients. Fingers were prepared by joining dynamic augmentation and latent flexion (klinert convention) in a defensive support for the initial 3 weeks after medical procedure.

The subsequent period found the middle value of 13 months. In view of the first Strickland standards, the outcomes were fantastic in 17 fingers, great in 9, (indicated $96 \%$ superb and $4 \%$ great). The normal flexion was $62^{\circ}$ for distal interphalangeal joints and $90^{\circ}$ for proximal interphalangeal joints.

Moriyalet al [6], announced the consequence of 101 flexor ligament wounds utilizing Klinert convention as post-usable restoration program. The eventual outcome did not regard superb scopes of movement in 81 fingers $(80 \%)$, reasonable in 11 , and poor in 9 fingers $(9 \%)$ by the Strickland's models, with the crack in six fingers $(5.4 \%)$. The six burst ligaments were appraised as a helpless outcome.

In Savage et.al [3] and Osada et.al [13] in their investigations there were no revealed cases had break they utilized six strands center stitch and early dynamic activation convention postoperatively. (Nonetheless, the pace of burst of different investigations was higher than our examination. LK Hung et.al [10] the crack rate was $6.5 \%$. They utilized altered Kissler in their convention of ligament fix and received early activation program postoperatively.In Moriyalet al [6], revealed the consequence of 101 flexor ligament wounds utilizing Klinert convention as post-usable recovery program. The bliss rate was $5.6 \%$ in their investigation. Sandow et.al [11] led an investigation utilizing a 4-strand stitch procedure and received early dynamic activation as postoperative restoration convention. The break rate was $4.6 \%$.

In our examination the utilization of six strand strategy we play out a horrendous tissue taking care of and solid fix with negligible gapping. This with the expansion of early dynamic movement treatment convention prompts positive outcomes with insignificant attachment arrangement.

Commonly in our investigation patients were rebellious and included the fixed fingers in their work early. The announced break rate from our arrangement was $(4 \%)$.

\section{Conclusion}

Utilizing multi-strand flexor ligament fix is better than traditional 2-strands fix in term of last useful reach and less pace of crack flexor ligaments. Watchword Early assembly - six-strand.

\section{References}

[1] Y. F. Wu, J. B. Tang. Recent developments in flexor tendon repair techniques and factors influencing strength of the tendon repair. The Journal of Hand Surgery(European Volume), Vol.39E (1, PP.6-19, 2014.

[2] M. Sirotakova, D. Elliot. Early active mobilization of primary repairs of flexor plilicis longus tendon with two Kessler two-strand core sutures and a strengthened circumferential suture .j Hand Surg\{Br\}, Vol.29, PP.531-535, 2004.

[3] R. Savage, G.Risitango. Flexor tendon repair using six stand method of repair and early active mobilization, Journal of Hand Surgery (British Volume), Vol.14B , PP.396-399, 1989.

[4] M.Karen, Pettengill. The Evolution of Early Mobilization of the Repaired Flexor Tendon. J HAND THER, Vol.18, PP.157-168, 2005.

[5] Hari Venkatramani, Vigneswaran Varadharajan, Praveen Bhardwaj, Aashish Vallurupalli, S. Raja Sabapathy. Flexor tendon injuries, J Clin Orthro Trauma. Sep-Oct, Vol.10(5, PP.853-861, 2019.

[6] K. Moriya, T. Yoshizu, Y. Maki, etal . Endo Clinical outcomes of early active mobilization following flexor tendon repair using the six-strand technique: short- and long-term evaluations The Journal of Hand Surgery (European Volume), Vol.40E(3), PP.250-258, 2015.

[7] J.W.Strickland. the scientific basis for advances in flexor tendon surgery. J Hand Ther, Vol.18, PP. 94110, 2005.

[8] S. Christiana, T. Tsu-Min. Clinical Results of Flexor 
Tendon Repair in Zone II Using a Strand Double Loop Technique .J Hand Microsurg , Vol.7(1), PP.25-29, 2015.

[9] G.L. Hoffmann, U. Buchler, E. Vogelin. Clinical results of flexor tendon repair in zone 2 using a sixstrand double loop technique compared with a twostrand technique. J Hand Surg Eur, Vol.33(4), PP.418-22(6), 2008.

[10] Ref LKHung, K.W. Pang. Active mobilization after flexor tendon repair: comparison of results following injuries in zone 2 and other zones. Journal of Orthopedic Surgery. Vol.13(2), PP.158-163, 2005.
[11]M. J. Sandow, M.McMahon. Active mobilization following single cross grasp four-strand flexor tenorrhaphy (Adelaide repair) The Journal of Hand Surgery (European Volume), Vol.36E(6, PP.467-47, 2011.

[12] O. Denju, T. Satoshi F Kazuya. Flexor Tendon Repair in Zone II With 6-Strand Techniques and Early Active Mobilization. J Hand Surg, Vol.31A, PP.987-992, 2006.

[13]D. Osada, S. Fujita, K. Tamai, T. Yamaguchi, A. Iwamoto, K. Saotome, J. Hand Surg Am , Vol.31(6, PP.987-992, 2006. 